\title{
Novel method for the removal of organic halogens from process
}

\section{wastewaters enabling water reuse}

Andras Jozsef Toth ${ }^{*}, 1$, Eniko Haaz ${ }^{1}$, Tibor Nagy ${ }^{1}$, Ariella Janka Tarjani ${ }^{1}$, Daniel Fozer ${ }^{1}$, Anita Andre $^{1}$, Nora Valentinyi ${ }^{1}$, Peter Mizsey ${ }^{1,2}$

${ }^{1}$ Environmental and Process Engineering Research Group, Budapest University of Technology and Economics, H-1111, Hungary, Budapest, Müegyetem rkp. 3.

Dr Andras Jozsef Toth PhD: +36 1463 1494, ajtoth@envproceng.eu

Ms Eniko Haaz: +36 1463 1494, eniko.haaz@mail.bme.hu

Dr Tibor Nagy PhD: +36 1463 1203, tibor.nagy@ mail.bme.hu

Ms Ariella Janka Tarjani: +36 1463 1203, tarjani.ariella@mail.bme.hu

Mr Daniel Fozer: +36 1463 1203, fozer.daniel@ mail.bme.hu

Ms Anita Andre: +36 1463 1203, anita.andre@ mail.bme.hu

Ms Nora Valentinyi: +36 1463 2035, n.valentinyi@mail.bme.hu

Prof Dr habil Peter Mizsey DSc: +36 1463 1396, mizsey@mail.bme.hu

${ }^{2}$ Department of Fine Chemicals and Environmental Technology, University of Miskolc, H-3515, Hungary, Miskolc, Egyetemváros C/1 108.

Prof Dr habil Peter Mizsey DSc: +36 46565 091, kemizsey@uni-miskolc.hu

* Corresponding author. E-mail address: ajtoth@envproceng.eu, Tel: +36 1463 1494; Fax: +36 1 4633197 


\begin{abstract}
The industrial production unavoidably generates waste in many cases but that should be recycled and reused following the principle of circular economy. New waste treatment methods or green technologies with zero waste should be developed in order to solve this problem. Since zero emission technology is a difficult task, it is rather typical that waste treatment process is developed. A typical example can be found in pharmaceutical industries because these plants generate wastewaters with high organic content, so-called process wastewaters. These waters should be definitely treated before discharging, their organic content must be removed and then the process wastewater may be usually allowed into the sewer. Nowadays, the physicochemical methods are increasingly used since they have a smaller footprint compared to that of the biological treatments. On the other hand, the polluting organic substances can be recovered and recycled or reused. In our novel method distillation is applied that is based on relative volatility differences of the individual components. The more volatile organic pollutants of the treated process wastewaters are obtained as the top product of the distillation, preferably in reusable form. The bottom product of distillation, namely the process wastewater should satisfy the discharge limits. Our novel innovative method is developed to remove and reuse the organically bound halogens (AOX) and to reduce the chemical oxygen demand (COD) below the emission limit of process wastewaters. Our method is implemented and this well-planned industrial apparatus meets the requirement of the Sustainable Water Solutions and Circular Economy, and moreover the payback time of the investment is less than two years.
\end{abstract}

\title{
Keywords
}

Process wastewater; AOX removal; Dichloromethane; Distillation; Industrial column; Circular economy 


\section{Introduction}

The treatment of process wastewaters (PWWs) is difficult, because there are other problems besides the large quantity of by-products [1,2]. In many cases the chemical PWWs create azeotropic mixtures, where the microbes in the conventional activated sludge are not able to convert the substances into their own nutrition. Furthermore the biological treatment is often not officially authorized [3]. On the other hand, if the biological treatment is considered, there is no chance for the recovery of the polluting compounds. In many cases the PWW fees are very significant and the incineration is also expensive because of the high water content of the samples. Therefore cheaper alternative methods are needed to solve the problem $[2,4,5]$.

The large amount of process wastewater with adsorbable organically bound halogens (AOX) content means serious problem in pharmaceutical industry. AOX is a sum parameter which indicates the overall level of organic halogen compounds (chlorine, bromine and iodine) in water samples. The emission of AOX into the water in Europe by different industry sectors are shown in Table 1, highlighting the chemical industries in Table 2. 
Table 1 The emission of AOX into the water by industry sectors/activity in Europe in 2010 [6]

\begin{tabular}{lcccc}
\hline \multirow{2}{*}{ Industry sector } & \multicolumn{2}{c}{ Installation } & \multicolumn{2}{c}{ AOX emission } \\
& No. & $\%$ & ton & $\%$ \\
\hline Urban wastewater treatment & 232 & 62 & 1045 & 25 \\
Paper and wood & 61 & 16 & 1997 & 48 \\
Chemical industry & 33 & 9 & 353 & 8 \\
Other sectors/activities & 26 & 7 & 179 & 4 \\
Other waste and wastewater management & 22 & 6 & 591 & 15 \\
\hline Total & 374 & & 4165 & \\
\hline
\end{tabular}

Table 2 The emission of AOX into the water by industry sectors/activity in Europe in 2010 [6]

\begin{tabular}{lcccc}
\hline \multirow{2}{*}{ Chemical industry } & \multicolumn{2}{l}{ Installation } & \multicolumn{2}{c}{ AOX emission } \\
& No. & $\%$ & ton & $\%$ \\
\hline Basic organic chemicals & 21 & 64 & 314 & 89 \\
Basic inorganic chemicals & 6 & 18 & 25 & 7 \\
Other chemicals & 6 & 18 & 14 & 4 \\
\hline Total & 33 & & 353 & \\
\hline
\end{tabular}

The chemical sector of EU countries generated 353 ton AOX waste in 2010. Within this sector, the production of basic organic chemicals was responsible for almost $90 \%$ of all AOX emissions [6]. It is important to emphasize that many organic halogen compounds are persistent and/or toxic. The AOX method has several advantages, for example it is a very simple and cheap measurement when 
it is compared to the alternative methods of measuring levels of individual compounds [6].

The advised treatment techniques of AOX removal methods from PWWs: chemical oxidation (pretreatment), wet oxidation (pretreatment), chemical hydrolysis, nanofiltration/reverse osmosis, adsorption [7-9], extraction, evaporation, pervaporation [10, 11], stripping, incineration and distillation $[6,12]$. Air stripping and its alternative method, steam stripping provide high efficiency up to $99.9 \%$ volatile organic compounds (VOC) and AOX removal $[13,14]$.

\subsection{Distillation for treatment of process wastewaters}

The distillation of VOCs significantly reduces the chemical oxygen demand (COD) of process wastewater. The volatile chemical oxygen demand (VOC-COD) can be enriched in the distillate [2, $6,15]$. The AOX could be removed with distillation too, but the process should be carried out carefully [16]. This study investigates a physicochemical approach for recycling wastewaters by applying distillation. The concept of this method is based on the difference of the relative volatilities of individual components in the wastewater. Figure 1 introduces a distillation schema for treatment of PWW with AOX and/or VOC content. The main advantages of process wastewater distillation are the possibility of material recycling and removability of refractory and/or toxic organic compounds. The disadvantage is the energy requirements, which can be reduced significantly if the feed is preheated with the bottom product as a kind of energy integration $[2,6]$. 


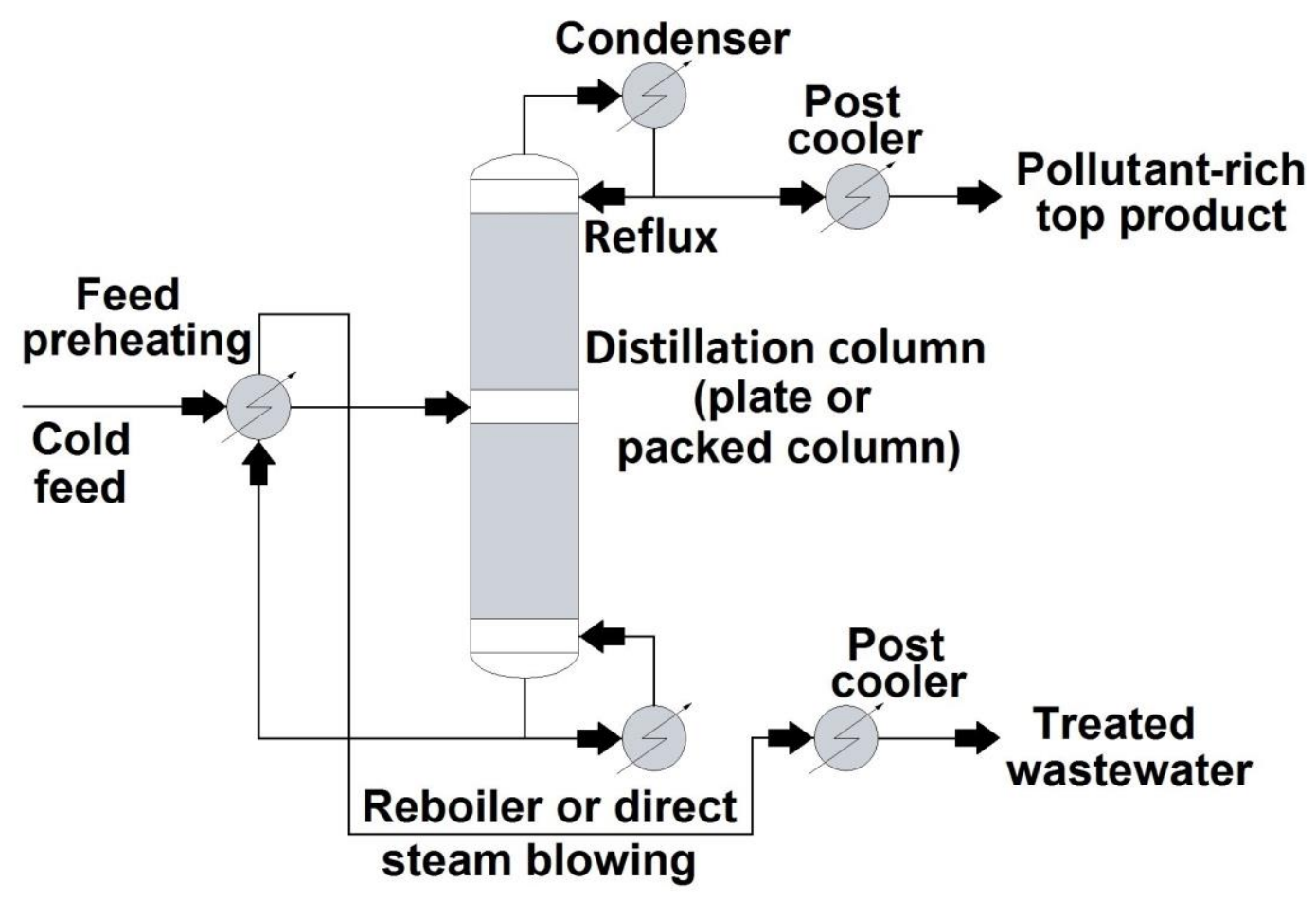

Figure 1 General schema of the process wastewater distillation [17]

The aim of this study is to introduce a method for treatment of PWW with $\sim 6000 \mathrm{ppm}$ AOX concentration and $\sim 16000 \mathrm{mgO}_{2} / \mathrm{L}$ COD. Laboratory, pilot experiments and industrial application are also demonstrated. The target of the treatment is to reduce the AOX below $8 \mathrm{ppm}$ (discharge limit) and $\mathrm{COD}$ below $1000 \mathrm{mgO}_{2} / \mathrm{L}$ to channeling the PWW. These emission values are the regulation limits, as it can be found in 28/2004. (XII. 25.) Ministry of Environment Regulation [18].

The emission limits for process wastewaters are extremely strict and the fine is high. If process wastewater of organic halide content is channelled by the company it can be either closed or punished with extremely high penalty. So it is essential for the manufacturer to develop such waste treatment method that is capable to fulfil the emission limits and maintain the economic and the environmental conscious industrial production.

According to the literature study, the largest phase of PWW can be recycled/reused using our 
elected method, which is distillation [2, 15, 19, 20]. Figure 2 summarizes the recommended treatment methods in the case of high content COD and AOX PWWs.

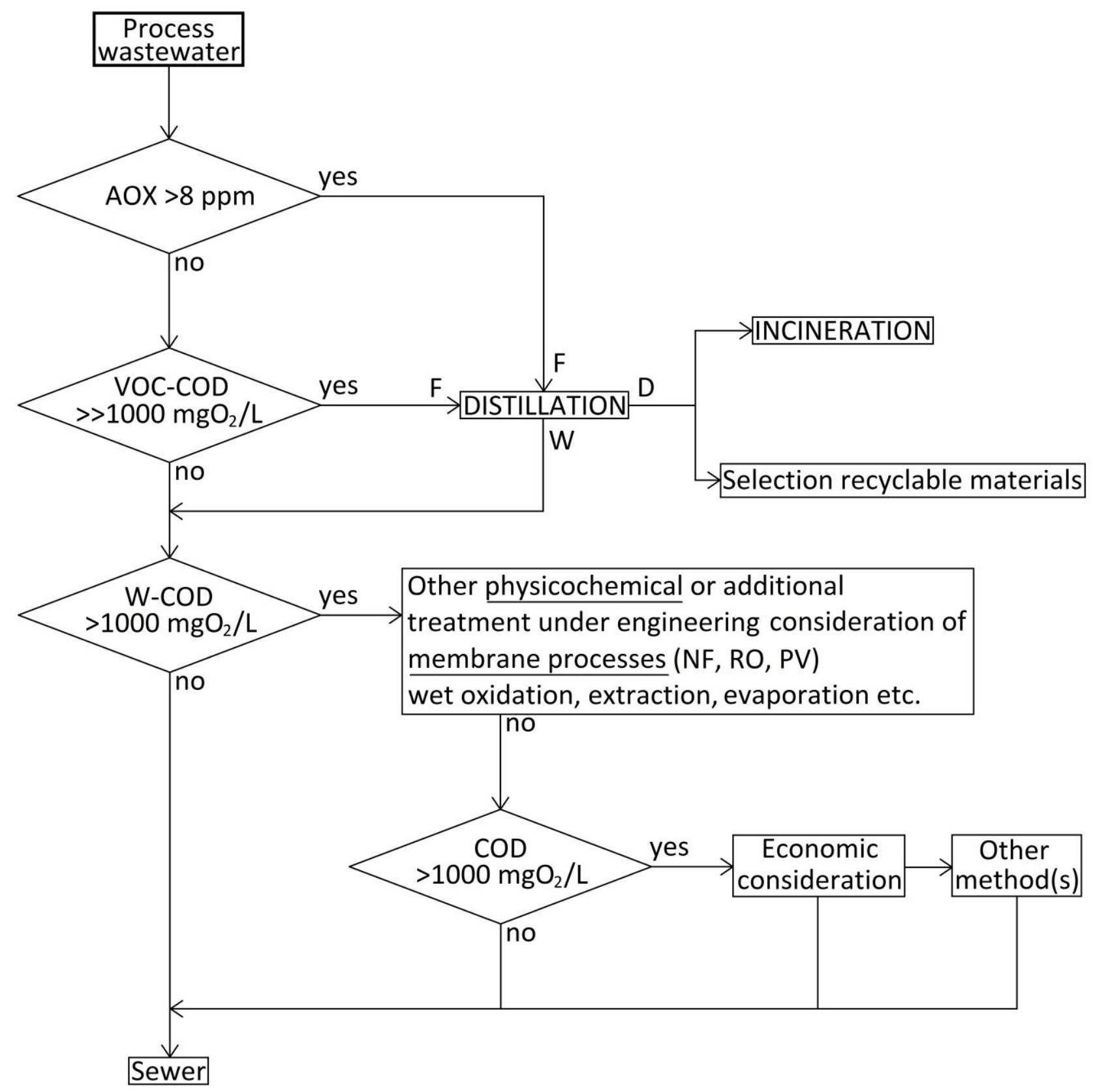

Figure 2 Strategy for process wastewater treatment methods [17]

(F: feed, D: distillate, W: bottom product)

It can be stated, our method follows the principles of circular economy (see Figure 3). Circular economy is an industrial economy that follows natural life cycles. In such way there is no waste 
production, but one product of the link becomes the resource of the following one leading towards a closed cycle [21]. The regeneration of PWWs can be solved locally in the factory with the introduction of waste treatments. The aim is to increase the recycle rate of the organic material of PWW and after that significantly less residual waste have to be disposed with incineration (cf. Figure 2).

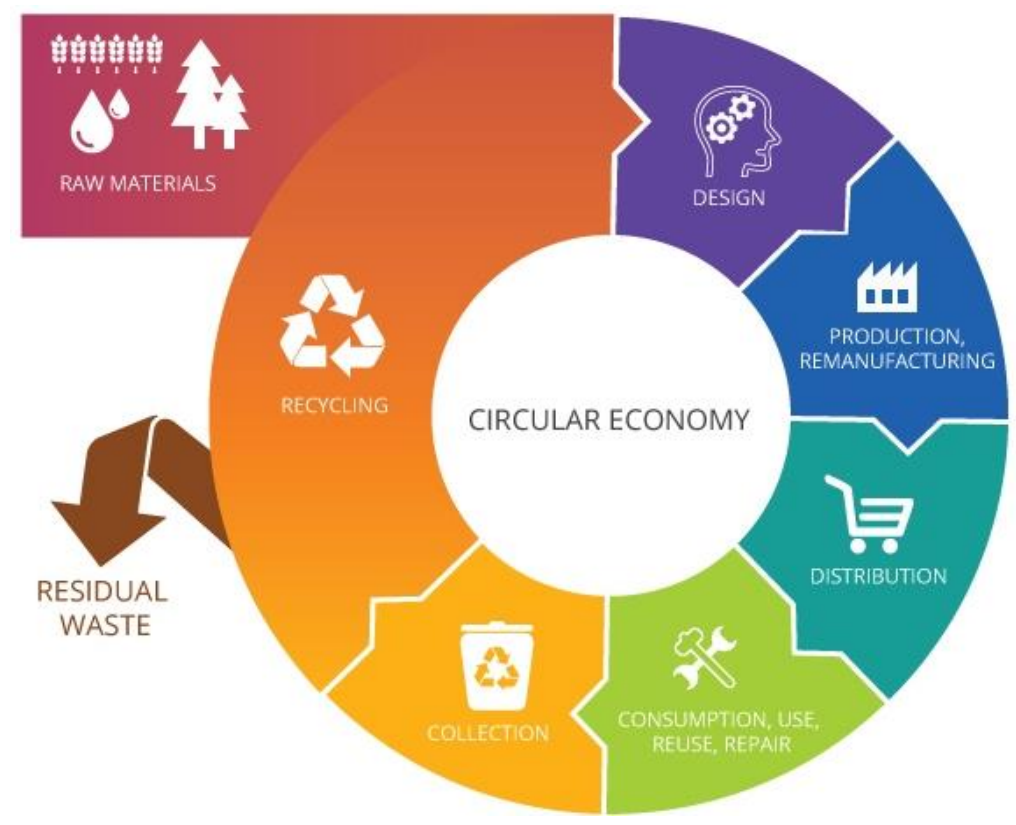

Figure 3 Flowsheet of circular economy [21]

It is clear by now that the process wastewaters should be rather treated with physicochemical methods than with biological ones. In the case of process wastewater treatment, the most applicable physicochemical method is based on the differences of relative volatilities. In this case the volatile organic pollutants can be removed by heating.

Designing such a method is a process design activity. It needs creativity, innovation, experience, simply to say engineering excellence. 


\section{Materials and methods}

Table 3 contains the polluting compounds of real industrial PWW samples from pharmaceutical sector. The amount of dry substance is not significant, but the COD values are so far from the emission limit. It can be seen halogen components, methanol, acetone and dry substance cause the high COD in initial PWW. Furthermore, the average density is $1.02 \mathrm{~g} / \mathrm{cm}^{3}$ and $\mathrm{pH}$ is 6.7 . Continuous operations were examined, because of the large amount of PWW, which is 570 ton/year.

Table 3 Main parameters of process wastewater samples

\begin{tabular}{cccccc}
\hline & \multicolumn{3}{c}{ Feed composition [ppm] } & Dry substance & COD \\
Sample & AOX & Methanol & Acetone & {$[\%]$} & {$\left[\mathrm{mgO}_{2} / \mathrm{L}\right]$} \\
\hline 1 & 5720 & 2330 & 3530 & 1.02 & 15200 \\
2 & 6630 & 2110 & 3580 & 0.59 & 14800 \\
3 & 5390 & 1980 & 2940 & 1.10 & 17300 \\
4 & 5530 & 1990 & 3450 & 0.33 & 15300 \\
5 & 6570 & 2050 & 2760 & 0.51 & 16400 \\
\hline Average & 5968 & 2092 & 3252 & 0.71 & 15800 \\
Deviation & 589 & 143 & 375 & 0.33 & 1027 \\
\hline
\end{tabular}

The distillation of process wastewater is containing organic solvents, especially halogenated organic compounds behave as the distillation of mixtures with limited solubility. $99.8 \%$ of AOX is Dichloromethane (DCM), further halogen compounds in the PWW can be found in Table 4. DCM is a toxic volatile compound which is found in the wastewater and ground water and widely used as a solvent in chemical industry. It is potentially carcinogenic for humans and induces cancer in 
animals [12]. It can be determined, every pollution compound belongs to the group of VOC [22, 23].

Table 4 AOX components in PWW

\begin{tabular}{lcccc}
\hline Component name & CAS & ppm & AOX\% & Azeotropic T-bp $\left[{ }^{\circ} \mathrm{C}\right]$ \\
\hline Dichloromethane & $75-09-2$ & 5956 & 99.8 & 38.1 \\
Trichloroethylene & $79-01-6$ & 5.4 & 0.09 & 73.1 \\
1,2-Dichloroethane & $107-06-2$ & 3.0 & 0.05 & 71.6 \\
Chloroform & $67-66-3$ & 1.8 & 0.03 & 56.3 \\
Tetrachloroethylene & $127-18-4$ & 1.2 & 0.02 & 88.5 \\
Carbon tetrachloride & $56-23-5$ & 0.6 & 0.01 & 66.8 \\
\hline
\end{tabular}

They form minimum boiling heterogeneous azeotropic with water [24, 25]. Figure 4 shows the vapor-liquid equilibrium (VLE) of DCM-Water mixture. 


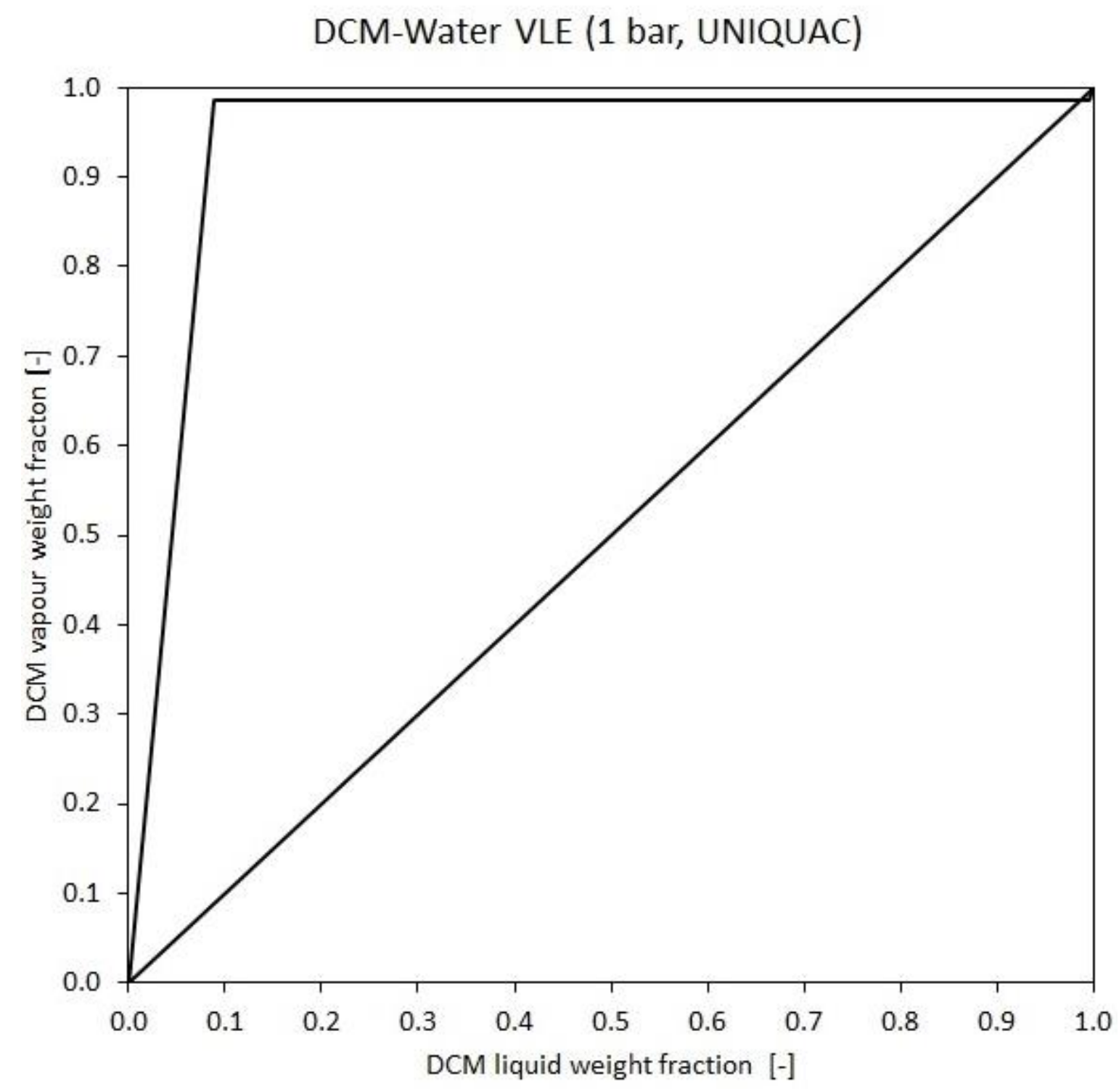

Figure 4 Dichloromethane-water VLE diagram at 1 bar

It can be seen 98.5 weigh percent dichloromethane means the azeotropic point. With other words, steam distillation is taking place where the Raoult's law is not applicable, however, the sum of the partial pressure of the compounds determines the circumstances. It results in a temperature which is always below than $100^{\circ} \mathrm{C}$ in the process wastewater distillation.

The process design steps are based on mathematical modelling and experiments. The modelling helps to reduce the solution space and the promising alternatives can be selected. However these 
alternatives must be tested and investigated by experiments. First, laboratory experiments and then experiments on the pilot plant scale were carried out.

Before the experiments, flowsheet simulations were carried out with flowsheet simulator (ChemCAD) to minimize the solution space, the required number of experiments and to find out the proper parameters of the unit operations. UNIQUAC method [26-29] was used for calculation of highly non-ideal vapour-liquid equilibria. The optimal mass flow rates, reflux ratio, heating and cooling requirements can also be determined [30]. Rectifying (upper) section is required for enrichment of AOX and other VOC-COD in PWW. The pollutant compounds must be also reduced with stripping (lower) section of column, so the PWW should be fed at the middle of the column.

Laboratory column was built to develop the treatment method (see Figure 5). 


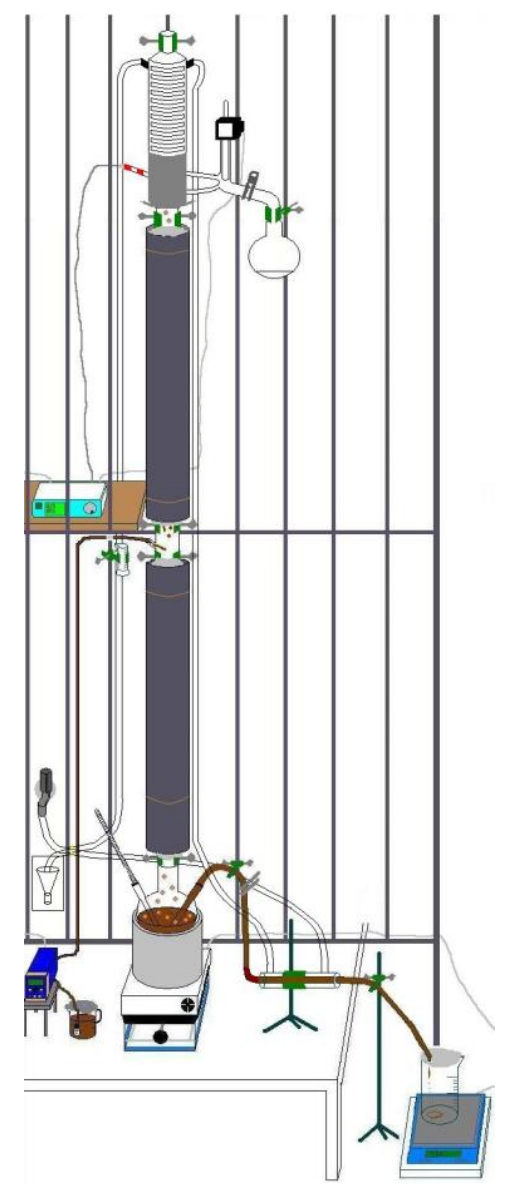

Figure 5 Laboratory column in continuous operation [31]

The main parameters of the laboratory experimental column can be seen in Table 5. The column had 10 theoretical plates according to a measurement which was carried out with methanol-water mixture. The PWW feed was not preheated and the column heating was controlled with heating basket. 
Table 5 Main parameters of laboratory column

\begin{tabular}{lc}
\hline Height of column & $0.7 \mathrm{~m}+0.65 \mathrm{~m}$ \\
Diameter of column & $0.04 \mathrm{~m}$ \\
Type of packing & Raschig-ring, 4 mm \\
Pump & Prominent GALA1005 \\
Theoretical plates & 5 \\
Feed plate & Iludest RT-2 \\
Reflux timer & heating basket (300 W)
\end{tabular}

After the laboratory experiments pilot distillation had to be carried out to determine which industrial equipment can be designed [2]. Figure 6 shows the pilot column for treatment of PWW. 


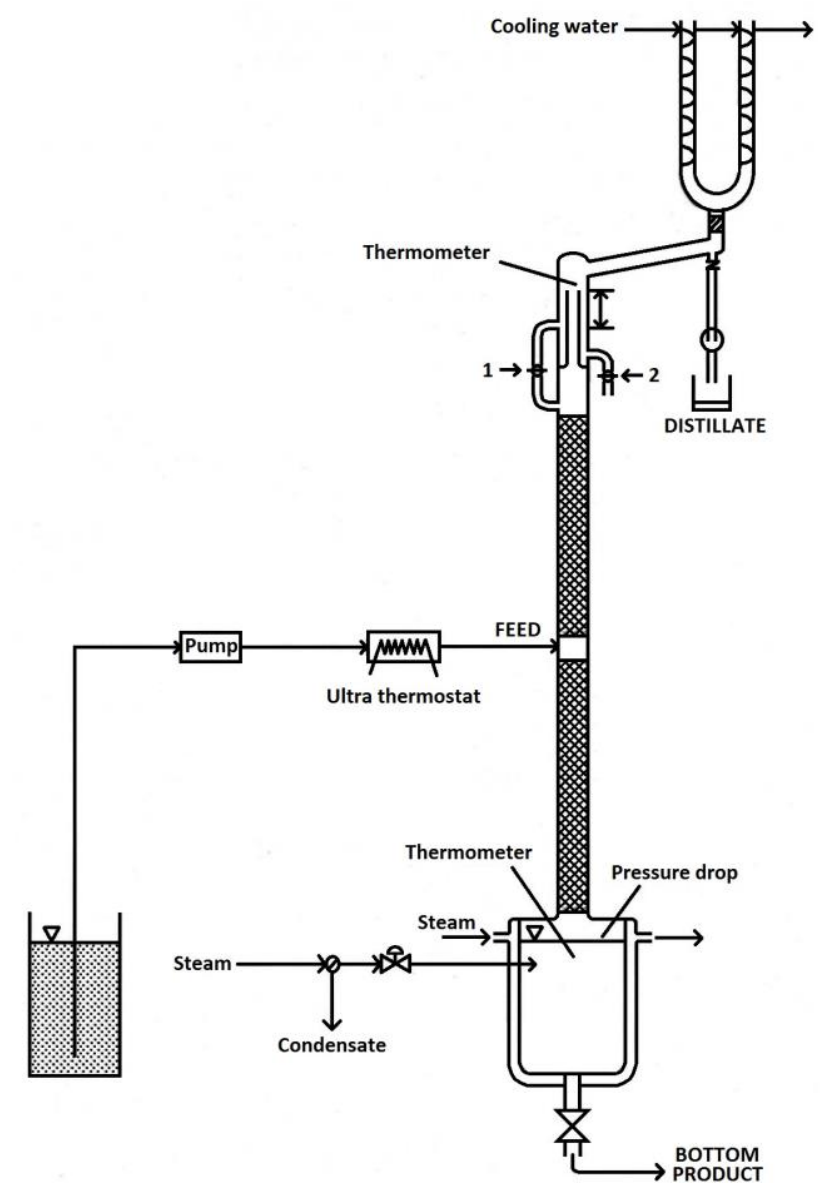

Figure 6 Pilot column with direct steam injection [17]

The pilot column had $3 \mathrm{~m}$ high packing of Sulzer Mellapak 750 type structured packing, which was equivalent to 14 theoretical plates in our case. Direct injection of the steam was applied for the heating of the kettle type reboiler. In the pilot plant laboratory the feed was preheated with ultra thermostat but in the industrial design the heat integration was considered. Further information can be found in Table 6. 
Table 6 Main parameters of the pilot column

\begin{tabular}{lc}
\hline Height of column & $1.5 \mathrm{~m}+1.5 \mathrm{~m}$ \\
Diameter of column & $0.07 \mathrm{~m}$ \\
Type of packing & Sulzer Mellapak 750 \\
Pump & 14 \\
Theoretical plates & 7 \\
Feed plate & Iludest RT-2 \\
Reflux timer & direct steam injection (2 bar) \\
Heating &
\end{tabular}

The laboratory and pilot experiments were carried out with same steps. First of all, the column was heated up with reboiler until constant distillate and bottom temperatures in total reflux mode, then process wastewater was fed into column in modelled stream, in parallel reflux controller was switch on. 3 to 4 hours steady state was examined all case of settings. Every half hour, during the experiments sampling was executed. Temperatures, mass and component flowrates were also examined.

On the basis of our experimental results and observations an industrial distillation column was designed with 17 theoretical plates and structured packing. The main parameters of the column can be seen in Figure 7. The feed tray location was located at the middle of the column and even $500 \mathrm{~L} / \mathrm{h}$ PWW can be treated. Direct steam of 2 bars was injected into the bottom. The implementation of measurement was the same with pilot column case from heating up the column to steady state. The steady state was reached within 2 hours. 


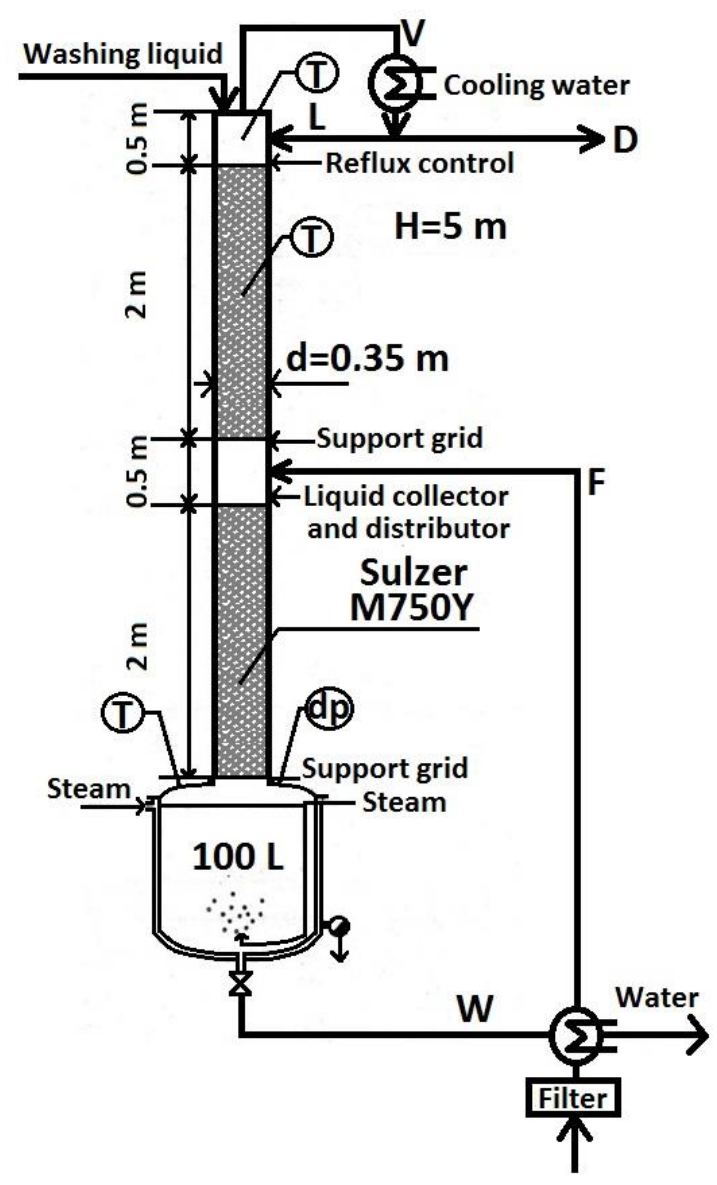

Figure 7 Schematic figure of the industrial column

The pollutant content of the feed, distillate and bottom product were measured with Shimadzu GC2010Plus+AOC-20 autosampler gas chromatograph with an Agilent CP-SIL-5CB (30 m x 0.32 $\mathrm{mm} \times 4.0 \mu \mathrm{m})$ column connected to a flame ionization detector and EGB HS 600 headspace apparatus was used for sample preparation. The injector and detector were thermostated to $250^{\circ} \mathrm{C}$ and the column temperature was kept at $60^{\circ} \mathrm{C}$. Pressure of carrier nitrogen, air and hydrogen gases were kept at 120, 60 and $50 \mathrm{kPa}$. The AOX was determined with Mitsubishi TOX-100 apparatus and the COD was measured by ISO 6060:1991. 


\section{Results and discussion}

\subsection{Experimental evaluation}

In the evaluation part, the best available results are presented. Table 7 and Table 8 show the optimized simulated tests and their measured results. It can be seen that the dry substance left in the bottom product, it was not detected in distillate. The simulation verification can be taken with objective function (OF), which is minimized the deviation of the simulated and the measured values.

OF $=\sum_{i=1}^{n}\left(\frac{D \text { or } W_{\text {measured }}-D \text { or } W_{\text {simulated }}}{D \text { or } W_{\text {measured }}}\right)^{2}$

The standard deviations (SDV) of measured data are also given in Table 7, 8 and 10. The comparison shows the accuracy also in laboratory, pilot and industrial cases.

Table 7 Comparison of modelling and experimental results in the case of laboratory column

\begin{tabular}{lcccccccccc}
\hline \multirow{2}{*}{ Laboratory column } & \multirow{2}{*}{ Feed } & \multicolumn{2}{c}{ Simulated data } & \multicolumn{4}{c}{ Measured data } & \multicolumn{2}{c}{ OF } \\
\cline { 3 - 9 } & & D & W & D & D - SDV & W & W - SDV & D & W \\
\hline AOX [m/m\%] & 0.60 & 95.95 & 0.001 & 95.92 & 0.02 & 0.0006 & 0.0001 & $1.18 \mathrm{E}-07$ & $4.44 \mathrm{E}-01$ \\
Methanol [m/m\%] & 0.21 & 0.042 & 0.032 & 0.045 & 0.004 & 0.038 & 0.004 & $4.43 \mathrm{E}-03$ & $2.49 \mathrm{E}-02$ \\
Acetone $[\mathrm{m} / \mathrm{m} \%]$ & 0.33 & 0.001 & 0.077 & 0.013 & 0.001 & 0.043 & 0.02 & $8.56 \mathrm{E}-01$ & $6.25 \mathrm{E}-01$ \\
Water $[\mathrm{m} / \mathrm{m} \%]$ & 98.16 & 4.004 & 99.18 & 4.022 & 0.03 & 99.21 & 0.01 & $1.98 \mathrm{E}-05$ & $8.19 \mathrm{E}-08$ \\
Dry substance [m/m\%] & 0.71 & 0 & 0.71 & 0 & 0 & 0.71 & 0 & 0 & 0 \\
$\mathrm{~T}\left[{ }^{\circ} \mathrm{C}\right]$ & 20 & 35.6 & 99.9 & 35.2 & 0.01 & 99.9 & 0.01 & $1.29 \mathrm{E}-04$ & 0 \\
\hline
\end{tabular}


Table 8 Comparison of modelling and experimental results in the case of pilot column

\begin{tabular}{lcccccccccc}
\hline \multirow{2}{*}{ Pilot column } & \multirow{2}{*}{ Feed } & \multicolumn{2}{c}{ Simulated data } & \multicolumn{4}{c}{ Measured data } & \multicolumn{3}{c}{ OF } \\
\cline { 3 - 10 } & & D & W & D & D - SDV & W & W - SDV & D & W \\
\hline AOX [m/m\%] & 0.60 & 96.04 & 0.0003 & 95.99 & 0.04 & 0.0002 & 0.0001 & $2.41 \mathrm{E}-07$ & $2.50 \mathrm{E}-01$ \\
Methanol [m/m\%] & 0.21 & 0.017 & 0.009 & 0.016 & 0.002 & 0.012 & 0.003 & $7.72 \mathrm{E}-03$ & $6.25 \mathrm{E}-02$ \\
Acetone [m/m\%] & 0.33 & $3.51 \mathrm{E}-05$ & 0.011 & 0.007 & 0.001 & 0.015 & 0.006 & $9.90 \mathrm{E}-01$ & $8.22 \mathrm{E}-02$ \\
Water $[\mathrm{m} / \mathrm{m} \%]$ & 98.16 & 3.945 & 99.27 & 3.987 & 0.2 & 99.26 & 0.3 & $1.09 \mathrm{E}-04$ & $5.26 \mathrm{E}-09$ \\
Dry substance [m/m\%] & 0.71 & 0 & 0.71 & 0 & 0 & 0.71 & 0 & 0 & 0 \\
$\mathrm{~T}\left[{ }^{\circ} \mathrm{C}\right]$ & 30 & 36.9 & 99.9 & 36.5 & 0.01 & 99.9 & 0.01 & $1.20 \mathrm{E}-04$ & 0 \\
\hline
\end{tabular}

Table 9 represents the measured results of laboratory and pilot experiments too.

Table 9 Results of laboratory and pilot experiments

\begin{tabular}{|c|c|c|c|c|c|c|c|c|}
\hline \multirow{3}{*}{ Experiment } & \multicolumn{3}{|c|}{ Stream } & \multirow{2}{*}{$\mathrm{R}$} & \multicolumn{4}{|c|}{ PWW composition (W) } \\
\hline & $\mathrm{F}$ & $\mathrm{D}$ & $\mathrm{W}$ & & $\mathrm{AOX}$ & Methanol & Acetone & COD \\
\hline & {$[\mathrm{kg} / \mathrm{h}]$} & {$[\mathrm{kg} / \mathrm{h}]$} & {$[\mathrm{kg} / \mathrm{h}]$} & {$[-]$} & [ppm] & [ppm] & [ppm] & {$\left[\mathrm{mgO}_{2} / \mathrm{L}\right]$} \\
\hline Laboratory & 1.03 & 0.015 & 1.004 & 20 & 6 & 380 & 430 & 5810 \\
\hline Pilot & 5.00 & 0.16 & 4.75 & 10 & 2 & 120 & 150 & 1640 \\
\hline
\end{tabular}

It can be seen, the AOX concentration of the PWW can be reduced below 8 ppm with applying continuous distillation experiments. $63 \%$ reduction in initial COD value can be reached with laboratory experiment and $90 \%$ applying pilot column, but the value is above the emission limit $\left(1000 \mathrm{mgO}_{2} / \mathrm{L}\right)$ yet. The results of pilot experiment in the case of pollutant compositions and COD of process wastewater are more favourable because the condensation steam can dilute the bottom product and it can reduce further the COD and AOX [2]. The reflux ratio can be kept between 10 and 20 but at low distillate flow (1.5\% and 3\% of the feed) it does not result in a high reflux flow rate. Examining the streams, it can be determined the mass balance error can be kept under $2 \%$ in both cases. 


\subsection{Industrial implementation of AOX and VOC-COD removal column}

Tables $\mathbf{1 0}$ and $\mathbf{1 1}$ show the results of industrial column test.

Table 10 Comparison of modelling and experimental results in the case of industrial column (b. d. 1.: below detection limit)

\begin{tabular}{lccccccccc}
\hline \multirow{2}{*}{ Industrial column } & \multirow{2}{*}{ Feed } & \multicolumn{3}{c}{ Simulated data } & \multicolumn{3}{c}{ Measured data } & \multicolumn{2}{c}{ OF } \\
\cline { 3 - 10 } & & $\mathrm{D}$ & $\mathrm{W}$ & $\mathrm{D}$ & $\mathrm{D}-\mathrm{SDV}$ & $\mathrm{W}$ & W - SDV & D & W \\
\hline AOX $[\mathrm{m} / \mathrm{m} \%]$ & 0.60 & 95.99 & 0.00001 & 95.91 & 0.03 & b. d. 1. & - & $6.96 \mathrm{E}-07$ & - \\
Methanol $[\mathrm{m} / \mathrm{m} \%]$ & 0.21 & 0.016 & 0.004 & 0.015 & 0.001 & 0.005 & 0.001 & $4.44 \mathrm{E}-03$ & $4.00 \mathrm{E}-02$ \\
Acetone $[\mathrm{m} / \mathrm{m} \%]$ & 0.33 & $3.28 \mathrm{E}-05$ & $3.60 \mathrm{E}-02$ & 0.084 & 0.04 & 0.009 & 0.003 & $9.99 \mathrm{E}-01$ & $8.99 \mathrm{E}+00$ \\
Water $[\mathrm{m} / \mathrm{m} \%]$ & 98.16 & 3.994 & 99.25 & 3.991 & 0.3 & 99.28 & 0.04 & $5.53 \mathrm{E}-07$ & $6.86 \mathrm{E}-08$ \\
Dry substance $[\mathrm{m} / \mathrm{m} \%]$ & 0.71 & 0 & 0.71 & 0 & 0 & 0.71 & 0 & 0 & 0 \\
T $\left[{ }^{\circ} \mathrm{C}\right]$ & 30 & 36.7 & 99.9 & 36.3 & 0.01 & 99.9 & 0.01 & $1.21 \mathrm{E}-04$ & 0 \\
\hline
\end{tabular}

Table 11 Results of industrial measurements

(b. d. 1.: below detection limit)

\begin{tabular}{|c|c|c|c|c|c|c|c|}
\hline \multicolumn{3}{|c|}{ Stream } & \multirow{2}{*}{$\mathrm{R}$} & \multicolumn{4}{|c|}{ PWW composition (W) } \\
\hline $\mathrm{F}$ & $\mathrm{D}$ & $\mathrm{W}$ & & $\mathrm{AOX}$ & Methanol & Acetone & COD \\
\hline$[\mathrm{kg} / \mathrm{h}]$ & {$[\mathrm{kg} / \mathrm{h}]$} & {$[\mathrm{kg} / \mathrm{h}]$} & {$[-]$} & [ppm] & [ppm] & [ppm] & {$\left[\mathrm{mgO}_{2} / \mathrm{L}\right]$} \\
\hline 510 & 7 & 497 & 10 & b. d.l. & 50 & 90 & 500 \\
\hline
\end{tabular}

It can be seen the AOX was below detection limit (b. d. 1.) and COD was also below the emission limit in bottom product (W). Furthermore, mass balance error can be kept under $2 \%$.

After our modelling and experiments it can be stated, that in the case of the volatile organic pollutants can be removed with heating. Modelling and experiments prove that the best solution is based on the application of steam as heat source that stripes out the volatile organic compounds. Special attention is given to the organic halides because this is the only way to remove them. Such 
treatment is carried out in a rectification column and the top vapour stream is condensed, after that a part of the condensate is taken away, distillate, and partially refluxed back into the column.

With this method we can get the treated process wastewater in the bottom of the rectification column having less pollutants than the emission limit. In the top, the distillate, the polluting organic compounds can be obtained in high concentration. As far as the organic halides are considered our method is the only way to remove them.

Every kind of possible process wastewater was tested and a flexible rectification column was designed. Flexibility means, that the column should be able to operate in a wide range of wastewater loads. On the basis of laboratory and pilot plant experiments the proper rectification column was planned and completed. Industrial experts were involved into the design and implementation steps so the column can operate according to the expectations.

Key points of efficiency and economic aspects of our industrial process are highlighted, as follows.

Novelty, innovative engineering solutions of the method and apparatus:

- The condensing steam dilutes the bottom product and reduces the AOX and also COD below the emission limit. The halogen compounds are below the detection limit and COD is measured $\sim 500 \mathrm{mgO}_{2} / \mathrm{L}$ in PWW, so the sewer requirements of water are satisfied. Another unique feature of this method is that there is no need for designing a kettle/reboiler separate from the column, because direct steam injection can be applied for the heating of the kettle [2].

- On the other hand, the heat integration can reduce the energy demands, only $25 \mathrm{~kg} / \mathrm{h}$ steam is required for the process. The hot effluent wastewater is used for feed preheating, thus this 
separation process involves $90 \%$ energy savings.

- Last, but not least, the distillate can be utilized in other plant after a simple phase separation, as dichloromethane solvent because the column has rectifying section. So the process can adapt to circular economy concept with this recycle/reuse option.

Economic and social benefits of the method and apparatus:

- Very high wastewater fee must be paid, if this PWW is channelled without any treatment by pharmaceutical company, so there is essential for the manufacturer to develop waste treatment method to just the maintenance of its industrial production.

- The process of calculating of the wastewater fee can be found in 220/2004. (VII. 21) Government Regulation, Annex 2 [32]. It can be read that the specific penalty factor of AOX is an outstanding value, that is $250 \$ / \mathrm{kg}$ to comparison, there is $0.25 \$ / \mathrm{kg}$ in the case of COD emission.

- The economic benefits of the apparatus are supported by concrete data [33]. The investment cost of the optimized process was calculated according to the cost correlations of Douglas [34] with current $M \& S$ index. Investment costs of the distillation depend on different parameters: heat duties, the sizes of the column and heat exchangers, pump cost and purity of the products. The operating costs contain the annual costs of the steam and water consumption. 8000 hours/year continuous operation was selected for the calculation of the operating cost. 10-year amortization of investment cost was assumed for the total cost estimation [35]. The above-mentioned heat integration and lower steam consumption result favourable operating cost. Table $\mathbf{1 0}$ shows that, the column's payback time is only less than 2 years. 
Table 12 Cost parameters of the apparatus

\begin{tabular}{lc}
\hline Investment cost & 355000 USD \\
Operating cost/year & 73000 USD \\
Savings/year & 267000 USD \\
Payback time & 1 year 10 month
\end{tabular}

- The real benefit of the pharmaceutical company is even greater, because more different PWWs can be treated as well with this apparatus, especially it is suitable for alcohols (meanly methanol and ethanol) removal and recycling from water based mixtures.

- After installation process, another 4 columns were built according to this method, which indicate the success of the procedure. These columns operate successfully and economically in the chemical industry still today. We have 3 pharmaceuticals and 1 petrochemical references, the presented one in this text can be the only one in our public tender, which can demonstrate the technology.

It has to be stated that each case should be examined individually and experimentally since the dissolved substance can cause fouling in the column. Laboratory and pilot experiments are necessary to study the real vapour-liquid equilibria of PWW. Therefore, it is difficult to give the general limitations of the proposed method because it is different for every PWW case. 


\section{Conclusion}

In the different process industries special process wastewaters arise that contain significant amount of organic compounds, among them organic halides. These compounds have a significant effect on the environment and only physicochemical methods can be considered as treatment. Applying steam to stripping out the pollutants, the process wastewaters can be cleaned until the discharge limit and the polluting materials can be gained as product of the method. For this purpose a rectification column with enough flexibility is designed based on modelling and experiments. Industrial case study proves that the method can be successfully applied fulfilling the principle of the circular economy.

The column in the industry is currently operating far above the expectations. Huge practical and engineering considerations have resulted in this success of the developed novel method. The dichloromethane and AOX concentration of bottom product is under the detection limit because the application of direct steam results in a dilution effect. The distillate, after a simple phase separation, can be utilized in other plants as dichloromethane solvent. Heat integration reduces the energy demands and the operating costs. The hot effluent wastewater is used for feed preheating thus this separation process enables $90 \%$ energy savings. The payback time of the column is less than 2 years.

The waste treatment can be achieved locally in the factory and the chemical sector can be driven towards the circular economy. Because of the reuse of materials the cycle of manufacturing processes can be closed. The featured method reflects to the popular "think globally, act locally" slogan. 


\section{Acknowledgement}

The authors would like to acknowledge the financial support of János Bolyai Research Scholarship of the Hungarian Academy of Sciences, Swiss-Hungarian Cooperation Programme - SH 7/2/14 and OTKA 112699 project. This research was supported by the European Union and the Hungarian State, co-financed by the European Regional Development Fund in the framework of the GINOP2.3.4-15-2016-00004 project, aimed to promote the cooperation between the higher education and the industry and the ÚNKP-17-3-I New National Excellence Program of the Ministry of Human Capacities. 


\section{Nomenclature}

d

D

F

$\mathrm{H}$

No.

$\mathrm{R}$

$\mathrm{T}$

T-bp

W

Abbreviations

AOX

b. d. 1 .

COD

DCM

OF

ppm

PWW

SDV

VLE

VOC
Diameter of the column

Distillate

Feed

Height of the column

Number

Reflux ratio

Temperature

$\left[{ }^{\circ} \mathrm{C}\right]$

Boiling point

$\left[{ }^{\circ} \mathrm{C}\right]$

Bottom product

Adsorbable organically bound halogens

[ppm]

Below detection limit

Chemical oxygen demand

$\left[\mathrm{mgO}_{2} / \mathrm{L}\right]$

Dichloromethane

Objective function

Parts per million

Process wastewater

Standard deviation

Vapour-liquid equilibrium

Volatile organic compounds 


\section{References}

[1] P. Mizsey, Waste reduction in the chemical industry: a two level problem, J. Hazard. Mater., 37 (1994) 1-13.

[2] A.J. Toth, F. Gergely, P. Mizsey, Physicochemical treatment of pharmaceutical wastewater: distillation and membrane processes, Period. Polytech. Chem., 55 (2011) 59-67.

[3] J.N. Bhakta, Handbook of Research on Inventive Bioremediation Techniques, IGI Global, 2017.

[4] M.C. Belis-Bergouignan, V. Oltra, M. Saint Jean, Trajectories towards clean technology: Example of volatile organic compound emission reductions, Ecol. Econ., 48 (2004) 201-220.

[5] M. Getzner, The quantitative and qualitative impacts of clean technologies on employment, J. Clean. Prod., 10 (2002) 305-319.

[6] T. Brinkmann, G.G. Santonja, H. Yükseler, S. Roudier, L.D. Sancho, Best Available Techniques (BAT) Reference Document for Common Waste water and Waste Gas Treatment/Management Systems in the Chemical Sector, Industrial Emisssions Directive, 2010/75/EU, Integrated Pollution Prevention and Control, JRC Science for Policy Report, 2016.

http://eippcb.jrc.ec.europa.eu/reference/BREF/CWW_Bref_2016_published.pdf

[7] A. Bhatnagar, W. Hogland, M. Marques, M. Sillanpää, An overview of the modification methods of activated carbon for its water treatment applications, Chem. Eng J., 219 (2013) 499511.

[8] D. Das, V. Gaur, N. Verma, Removal of volatile organic compound by activated carbon fiber, Carbon, 42 (2004) 2949-2962.

[9] C. Moreno-Castilla, Adsorption of organic molecules from aqueous solutions on carbon materials, Carbon, 42 (2004) 83-94.

[10] S.X. Liu, L.M. Vane, M. Peng, Theoretical analysis of concentration polarization effect on VOC removal by pervaporation, J. Hazard. Sub. Res., 4 (2004) 1-21.

[11] B. Smitha, D. Suhanya, S. Sridhar, M. Ramakrishna, Separation of organic-organic mixtures by pervaporation - a review, J. Membrane Sci., 241 (2004) 1-21.

[12] M. Shestakova, M. Sillanpää, Removal of dichloromethane from ground and wastewater: A review, Chemosphere, 93 (2013) 1258-1267.

[13] A.J. Toth, P. Mizsey, Comparison of air and steam stripping: removal of organic halogen compounds from process wastewaters, Int. J. Environ. Sci. Te., 12 (2015) 1321-1330.

[14] M.K. Verma, R.K. Tyagi, Aeration of volatile organic compounds using gas dispersion impellers, J. Mech. Eng. Res., 4 (2003) 213-224.

[15] K. Koczka, P. Mizsey, New area for distillation: Wastewater treatment, Period. Polytech. Chem., 54 (2010) 41-45.

[16] J. Levec, A. Pintar, Catalytic wet-air oxidation processes: A review, Catal. Today, 124 (2007) 172-184.

[17] A.J. Toth, Liquid Waste Treatment with Physicochemical Tools for Environmental Protection, PhD Thesis, Budapest University of Technology and Economics, Budapest, 2015.

[18] 28/2004. (XII. 25.) Ministry of Environment Regulation https://net.jogtar.hu/jr/gen/hjegy_doc.cgi?docid=A0400028.KVV

[19] D.L. McCabe, M.A. Vivona, Treating process wastewater employing vacuum distillation using mechanical vapor recompression, Environ. Prog., 18 (1999) 30-33.

[20] P. Mizsey, K. Koczka, A. Tungler, Treatment of process waters with physicochemical techniques, Hung. J. Chem., 114 (2008) 107-113.

[21] M. Anastasio, The circular economy: practical steps to enhance the EU package, Green Budget Europe, Report, 2016.

http://green-budget.eu/wp-content/uploads/GBE-Circular-Economy-policy-briefing-.pdf 
[22] E.W. Flick, Industrial Solvents Handbook, Noyes Data Corporation, 1998.

[23] G. Wypych, Handbook of Solvents, Noyes Publications, 2001.

[24] J. Gmehling, U. Onken, Vapor-Liquid Equilibrium Data Collection: Aqueous-Organic Systems, DECHEMA, 1977.

[25] C. Marsden, Solvents And Allied Substances Manual With Solubility Chart, Cleaver-Hume and Elsevier, London, 1954.

[26] D.S. Abrams, J.M. Prausnitz, Statistical Thermodynamics of Liquid Mixtures: A New Expression for the Excess Gibbs Energy of Partly or Completely Miscible Systems, AIChE. J., 21 (1975) 116-128.

[27] A. Klamt, G.J.P. Krooshof, R. Taylor, COSMOSPACE: Alternative to conventional activitycoefficient models, AIChE J., 48 (2002) 2332-2349.

[28] L.D. Simoni, Y. Lin, J.F. Brennecke, M.A. Stadtherr, Modeling liquid-liquid equilibrium of ionic liquid systems with NRTL, electrolyte-NRTL, and UNIQUAC, Ind. Eng. Chem. Res., 47 (2008) 256-272.

[29] B. Wiśniewska-Goclowska, S.X.K. Malanowski, A new modification of the UNIQUAC equation including temperature dependent parameters, Fluid Phase Equilibr., 180 (2001) 103-113.

[30] A.J. Toth, A. Szanyi, K. Angyal-Koczka, P. Mizsey, Enhanced Separation of Highly Non-ideal Mixtures with Extractive Heterogeneous-azeotropic Distillation, Sep. Sci. Technol., 51 (2016) $1238-1247$.

[31] E. Cséfalvay, T. Benkő, N. Valentínyi, A.J. Tóth, J.M. Tukacs, I. Gresits, A. Kovács, L. Rácz, S. Solti, P. Mizsey, Should we worry about pouring petrol on the tyres?, Industrial Ecology, 3 (2015) 3-16.

[32] 220/2004. (VII. 21) Government Regulation.

https://net.jogtar.hu/jr/gen/hjegy_doc.cgi?docid=A0400220.KOR

[33] G. Réti, Globális célok - helyi megoldások az Egis környezetvédelmében, Ablakon Bedobott Pénz, KÖVET Egyesület, 12 (2014) 12-13.

[34] J.M. Douglas, Conceptual design of chemical processes, McGraw-Hill, New York, 1988.

[35] A.J. Toth, E. Haaz, T. Nagy, R. Tari, A.J. Tarjani, D. Fozer, A. Szanyi, K.-A. Koczka, L. Racz, G. Ugro, P. Mizsey, Evaluation of the accuracy of modelling the separation of highly non-ideal mixtures: extractive heterogeneous-azeotropic distillation, in: A. Espuña, M. Graells, L. Puigjaner (Eds.) Computer Aided Chemical Engineering, Elsevier, 2017, pp. 241-246. 